\title{
Adipose tissue fibrosis in human cancer cachexia: the role of TGF $\beta$ pathway
}

\author{
Michele Joana Alves ${ }^{1 *}$ (D), Raquel Galvão Figuerêdo ${ }^{1}$, Flavia Figueiredo Azevedo ${ }^{6}$, Diego Alexandre Cavallaro ${ }^{1,5}$, \\ Nelson Inácio Pinto Neto ${ }^{5}$, Joanna Darck Carola Lima', Emidio Matos-Neto', Katrin Radloff', \\ Daniela Mendes Riccardi ${ }^{1}$, Rodolfo Gonzalez Camargo', Paulo Sérgio Martins De Alcântara ${ }^{3}$, José Pinhata Otoch ${ }^{2,3}$, \\ Miguel Luiz Batista Junior ${ }^{4}$ and Marília Seelaender ${ }^{1,2}$
}

\begin{abstract}
Background: Cancer cachexia is a multifactorial syndrome that dramatically decreases survival. Loss of white adipose tissue (WAT) is one of the key characteristics of cachexia. WAT wasting is paralleled by microarchitectural remodeling in cachectic cancer patients. Fibrosis results from uncontrolled ECM synthesis, a process in which, transforming growth factor-beta (TGFB) plays a pivotal role. So far, the mechanisms involved in adipose tissue (AT) re-arrangement, and the role of TGF $\beta$ in inducing AT remodeling in weight-losing cancer patients are poorly understood. This study examined the modulation of ECM components mediated by TGF $\beta$ pathway in fibrotic AT obtained from cachectic gastrointestinal cancer patients.

Methods: After signing the informed consent form, patients were enrolled into the following groups: cancer cachexia (CC, $n=21)$, weight-stable cancer (WSC, $n=17)$, and control $(n=21)$. The total amount of collagen and elastic fibers in the subcutaneous AT was assessed by histological analysis and by immunohistochemistry. TGF $\beta$ isoforms expression was analyzed by Multiplex assay and by immunohistochemistry. Alpha-smooth muscle actin (aSMA), fibroblast-specific protein (FSP1), Smad3 and 4 were quantified by qPCR and/or by immunohistochemistry. Interleukin (IL) 2, IL5, IL8, IL13 and IL17 content, cytokines known to be associated with fibrosis, was measured by Multiplex assay.

Results: There was an accumulation of collagen and elastic fibers in the AT of CC, as compared with WSC and controls. Collagens type I, III, VI, and fibronectin expression was enhanced in the tissue of CC, compared with both WSC and control. The pronounced expression of aSMA in the surrounding of adipocytes, and the increased mRNA content for FSP1 (20-fold) indicate the presence of activated myofibroblasts; particularly in CC. TGF $\beta 1$ and TGF $\beta 3$ levels were up-regulated by cachexia in AT, as well in the isolated adipocytes. Smad3 and Smad4 labeling was found to be more evident in the fibrotic areas of CC adipose tissue.
\end{abstract}

Conclusions: Cancer cachexia promotes the development of AT fibrosis, in association with altered TGF $\beta$ signaling, compromising AT organization and function.

Keywords: Cancer cachexia, Fibrosis, Adipose tissue, Extracellular matrix, TGF $\beta$

\footnotetext{
* Correspondence: michelejalves@usp.br

${ }^{1}$ Cancer Metabolism Research Group, Institute of Biomedical Sciences,

University of Sao Paulo, Sao Paulo, Brazil

Full list of author information is available at the end of the article
} 


\section{Background}

Cancer cachexia is an irreversible syndrome in which involuntary weight loss occurs, due to skeletal muscle mass and adipose tissue wasting. This condition is associated with poor prognosis, and decreased survival [1, 2]. Cachexia is seldom diagnosed or treated, despite affecting around $80 \%$ of all cancer patients [3], and being the direct cause of $22-40 \%$ of cancer deaths $[4,5]$. The typical metabolic dysregulation acts in concert with the increase of inflammatory mediators $[6,7]$, as the syndrome develops in the manner of a chronic inflammatory state.

Profound wasting of WAT is frequently observed during cachexia, and recent evidence suggests that it precedes protein breakdown in the skeletal muscle or any decrease in food intake $[8,9]$. The WAT has been recognized as a highly dynamic organ [10-12]. Therefore, changes in WAT may be proposed as early markers of the syndrome, thus presenting a potentially valuable tool for precocious diagnosis. Previous studies $[9,13-16]$ have shown that the AT is deeply affected by local inflammation during cancer cachexia. Several pro-inflammatory factors, such as TNF $\alpha$, IL-1 $\beta$ and IL- 6 are up-regulated by in the adipose tissue during cachexia, and we have shown before [14-16], that the subcutaneous depot presents a relevant contribution to systemic inflammation as these factors reach the circulation.

Each particular anatomical depot of adipose tissue exhibits specific arrangement and functions, along with diverse morphology and varying density of adipocytes, of pre-adipocytes, of fibroblasts, of endothelial cells and of resident macrophages $[10,17]$. The extracellular matrix (ECM) is a complex network essential for tissue architecture and cell functioning $[10,18]$. ECM acts as one of the most important reservoirs of growth factors, metalloproteinases, collagens and fibronectin. Indeed, changes in ECM rapidly trigger signaling pathways controlling different cell functions, including development, migration, proliferation, apoptosis, and gene expression [19]. Among the different extracellular matrix components, collagen VI is highly expressed in the adipose tissue, and is considered as the key form secreted by adipocytes. The lack of collagen VI in col6 $\mathrm{KO}$ ob/ob mice results in the uninhibited expansion of individual adipocytes [20,21]. Studies with mice bearing the cachexia-inducing tumor MAC-16 show that adipocyte dimensions are reduced, the cell membranes disrupted, and that the tissue suffers fibrosis [9].

Fibrosis results from persistent inflammation, in which activated mechanisms for repair response lead to excessive accumulation of extracellular matrix components $[22,23]$. TGF $\beta$ is one of the key cytokines taking part in wound-healing and tissue fibrosis [24]. Binding of TGF $\beta$ to membrane receptors causes the assembly of a receptor complex that, in turn, phosphorylates SMAD proteins [25-27]. Through the action of SMADs on target genes, the induction of differentiation of fibroblasts into myofibroblasts takes place [28]. Myofibroblasts are contractile cells expressing alpha-smooth muscle actin $(\alpha-S M A)$, involved in the production of ECM proteins, such as collagen and fibronectin [29, 30].

Myofibroblast activation, proliferation and survival are also mediated by other pro-inflammatory cytokines: TNF, IL13, IL1 and TGF $\beta$ [31-34]. The microenvironment in fibrosis triggered by the TGF $\beta$ pathway often leads myofibroblasts to sustain uncontrolled deposition of extracellular matrix components, since these cells become resistant to the mechanisms of apoptosis [23].

Recently, we demonstrated that cachectic patients with gastrointestinal cancer show morphological rearrangement in the subcutaneous AT, resulting in adipocyte size reduction, AT atrophy, formation of fibrotic areas and immune cell infiltration [35]. In the current study, we hypothesized that the morphological changes in cancer cachexia concomitant with augmented expression of ECM elements occurs through enhanced signaling of the TGF $\beta$ pathway.

\section{Methods}

\section{Patient recruitment}

All subjects were selected between 2012 and 2015 at the ambulatory unit of the Surgical Medical Clinic at the University Hospital, after being scheduled for exploratory laparotomy or abdominal surgery $(n=212)$. The adopted exclusion criteria were: liver or kidney failure, AIDS, chronic inflammatory processes not related to cachexia, chemotherapy treatment (at the time), and chronic anti-inflammatory therapy. All the procedures were performed according to the Declaration of Helsinki, and were approved by the Ethics Committee of Research Involving Human Subjects of the Institute of Biomedical Sciences/University of Sao Paulo (1082/CEP) and by the Human Ethics Committee of the University Hospital/University of Sao Paulo (CEP 752/07). The fully informed written consent signature was obtained from every patient after a detailed explanation of the study. Following engagement in the study, patients were divided into three groups. The control group $(C)$ included weight stable patients subjected to surgical hernia removal. Patients diagnosed previously with gastrointestinal cancer were divided in two groups: Weight-stable Cancer Group (WSC) and Cachectic Cancer Group (CC). The WSC group was comprised of patients with greater than $5 \%$ body weight loss in the previous 6 months. CC group included the patients with gastrointestinal cancer and cachexia, characterized according to the following criteria: weight loss greater than $5 \%$ in fewer than 12 months, fatigue, anorexia; and abnormal biochemical parameters (increased inflammatory markers: C-Reactive 
Protein, anemia, and by low serum albumin) [1]. The questionnaire EORTC QLQ-C30 was applied to assess quality-of-life of all patients and the obtained data indicated a reduced overall quality-of-life in the cachectic group. A total of 153 patients were excluded from the study. Forty patients refused to participate. Further exclusion criteria were inconsistent data in questionnaires $(n=19)$ and BMI greater than $29.9 \mathrm{~kg} / \mathrm{m}^{2}(n=03)$. Patients of the control group showing inflammation (CRP $>5 \mathrm{mg} / \mathrm{L}$ ) $(n=27)$ and anemia $(n=01)$ were also excluded. Some patients were excluded due to unconfirmed diagnosis after the final pathological analysis, as well as due to insufficient adipose tissue sample allowing analysis, or which could not be matched with a corresponding blood sample $(n=63)$. A total of 59 patients were recruited into the study. Table 1 shows the characteristics of the study groups.

\section{Adipose tissue samples}

Subcutaneous adipose tissue was collected during the surgery procedure. Fat pad slices were rapidly frozen in dry ice and maintained in 4\% paraformaldehyde solution $(\mathrm{w} / \mathrm{v})$ for the histological analysis described below. For protein and gene expression, analyses of the samples were maintained at $-80{ }^{\circ} \mathrm{C}$, prior to processing.

\section{Plasma and serum measurements}

Approximately $20 \mathrm{ml}$ of blood were collected during admission at the hospital, and aliquots of both plasma and serum was stored at $-80{ }^{\circ} \mathrm{C}$ for later measurements. All analyses were performed in the automatic LABMAX $240^{\circ}$ equipment from Labtest, using commercial standards for Albumin (LABTEST), C-Reactive Protein (LABTEST), and hemoglobin (LABTEST).

\section{Protein expression of cytokines (TGF $\beta 1$, TGF $\beta 2$, TG $\beta 3$, TNFa, IL6, IL2, IL5, IL8, IL13, IL17) employing Luminex ${ }^{\circledR}$ technology}

Approximately 100-200 mg of the subcutaneous AT from each sample were homogenized in $300 \mu \mathrm{L}$ of ice-cold extraction protein buffer (10 mM Tris base, $0.01 \mathrm{mM}$ EDTA, $0.1 \mathrm{mM}$ Sodium Chloride and 1\% Triton X-100) to which a protease inhibitor cocktail was added (1 tablet/50 ml extraction buffer) (Roche Diagnostics). Protein extraction from isolated adipocytes was performed in the same way as described above, and the adipocytes were isolated following the adapted protocol from Rodbell [36]. The homogenate was then centrifuged at $18,000 \mathrm{~g}$ for $40 \mathrm{~min}$ at $4{ }^{\circ} \mathrm{C}$ and the fatty layer, discarded. The supernatant was stored in aliquots at $-80{ }^{\circ} \mathrm{C}$. Multi-species TGF $\beta 3$ plex

Table 1 General and clinical characteristics of studied groups

\begin{tabular}{|c|c|c|c|c|}
\hline & CONTROL & WSC & CC & $P$ value \\
\hline \multicolumn{5}{|l|}{ Clinical Parameters } \\
\hline N & 21 & 17 & 21 & \\
\hline Male/Female (n) & $16 / 5$ & $9 / 8$ & $13 / 8$ & \\
\hline Height (m) & $1.65 \pm 0.09$ & $1.62 \pm 0.09$ & $1.63 \pm 0.1$ & 0.6735 \\
\hline Age (years) & $54.10 \pm 14.89$ & $62.13 \pm 11.78$ & $63.00 \pm 11.0$ & 0.0642 \\
\hline Previous body mass (Kg) & $71.43 \pm 13.32$ & $73.50 \pm 13.28$ & $73.78 \pm 13.86$ & 0.8431 \\
\hline Current body mass (Kg) & $71.43 \pm 13.32$ & $69.28 \pm 12.19$ & $63.62 \pm 12.90$ & 0.1577 \\
\hline$\Delta$ Body mass $(\mathrm{Kg})^{\mathrm{a}}$ & $0.00[0.00 ; 0.00]$ & $0.00[-7.2 ; 0.0]$ & $-8.0[-12.50 ;-7.0]$ & $P<0.0001^{*}$ \\
\hline BMI $\left(\mathrm{Kg} / \mathrm{m}^{2}\right)$ & $25.82 \pm 3.27$ & $25.79 \pm 4.62$ & $23.68 \pm 3.49$ & 0.1558 \\
\hline \multicolumn{5}{|l|}{ Biochemical Parameters } \\
\hline C-Reactive Protein (mg/dL) & $0.11[0.0 ; 0.23]$ & $0.1950[0.0 ; 0.4]$ & $1.170[0.72 ; 1.3]$ & $<0.0001^{* * * \#}$ \\
\hline Albumin (g/dL) & $4.75[4.2 ; 5.1]$ & $4.37[4.05 ; 4.64]$ & $3.84[2.79 ; 4.58]$ & $0.0037^{* *}$ \\
\hline Hemoglobin (g/dL) & $15.25[13.9 ; 15.8]$ & $13.10[11.30 ; 14.08]$ & $11.80[9.15 ; 13.20]$ & $<0.0001^{* * * \#}$ \\
\hline IL6 (pg/ml) $)^{\mathrm{a}}$ & $0.00[0.00 ; 0.84]$ & $0.62[0.00 ; 1.77]$ & $4.10[1.25 ; 9.74]$ & $0.0008^{* * * \#}$ \\
\hline TNFa $(p g / m l)^{a}$ & $5.42[4.16 ; 6.15]$ & $6.01[3.92 ; 7.52]$ & $8.82[6.08 ; 13.87]$ & $0.028^{* *}$ \\
\hline IL2 $(p g / m l)^{\mathrm{a}}$ & ND & ND & ND & \\
\hline IL5 $(\mathrm{pg} / \mathrm{ml})^{\mathrm{a}}$ & $0.00[0.00 ; 0.73]$ & $0.00[0.00 ; 0.58]$ & $0.85[0.00 ; 1.36]$ & $p<0.0282^{\#}$ \\
\hline IL8 (pg/ml) ${ }^{\mathrm{a}}$ & $0.52[0.35 ; 2.16]$ & $4.79[2.02 ; 6.47]$ & $28.91[17.36 ; 68.86]$ & $p<0.0001^{* \#}$ \\
\hline IL13 (pg/ml) ${ }^{\mathrm{a}}$ & $0.03[0.03 ; 0.05]$ & $0.04[0.03 ; 0.04]$ & $0.07[0.02 ; 0.105]$ & 0.2947 \\
\hline $\mathrm{IL}_{1} 7^{\mathrm{b}}(\mathrm{pg} / \mathrm{ml})^{\mathrm{a}}$ & $0.79[0.71 ; 1.28]$ & $1.09[0.79 ; 1.41]$ & $1.56[0.87 ; 2.31]$ & 0.1305 \\
\hline
\end{tabular}

ANOVA one way; Data are presented as mean and S.E.M. ${ }^{a}$ Kruskal Wallis Test; Data presented as median, 1 st and 3st quartile. To cytokines content: Control ( $\left.n=17\right)$, WSC $(n=13)$, CC $(n=12) ;{ }^{b}$ Control $(n=10)$, WSC $(n=9)$, CC $(n=10) .{ }^{*} p<0.05{ }^{* *} p<0.003{ }^{* * *} p<0.0001$ CC vs Control; ${ }^{*} p<0.05$ CC vs WSC. TNFa tumour necrosis factor a; IL6 interleukin 6; IL2 interleukin 2; IL5 interleukin 5; IL8 interleukin 8; IL13 interleukin 13; IL 17 interleukin 17 
magnetic bead panel Milliplex ${ }^{\circ}$ MAP (TGFBMAG-64 K-03, Merck Millipore) was adopted to detect TGF $\beta 1$, TGF $\beta 2$, and TGF 33 . Before the assay, all samples were centrifuged to remove debris. For the TGF $\beta$ assay, all samples were acidified with $1 \mathrm{~N} \mathrm{HCL}$, after centrifugation. The Human Cytokine Magnetic Bead Panel Milliplex ${ }^{\circ}$ MAP (HCYTMAG-60 K-PX29, Merck Millipore) assay was employed to with plasma samples to detect the following cytokines: TNF $\alpha$, TNF $\beta$, IL1 $\beta$, IL2, IL5, IL13, IL15, and IL17. All working standards were submitted to serial dilutions, after the reconstitution of stock solutions. MagPlex ${ }^{\circ}$ beads were mixed with samples, and incubated by $2 \mathrm{~h}$ on a plate shaker at room temperature. After the incubation with detection antibody for $1 \mathrm{~h}$, the streptavidin-phycoerythrin was employed to detect the fluorescent reporter intensity from each microsphere that was linked to the sample. The Luminex $200^{\text {ma }}$ instrument with an $\mathrm{xMAP}^{\circ}$ technology system and $\mathrm{xPONENT}^{\circ}$ acquisition software were employed to capture component detection. MILLIPLEX ${ }^{\circ}$ Analyst 5.1 software was adopted integrating data acquisition and analysis.

\section{Gene expression}

Total RNA was extracted with Trizol $^{\circ}$ reagent (Invitrogen, Carlsbad, CA) following the manufacturer's recommendations. The concentration of total RNA was assessed with the Biotek $^{\circ}$ SynergyH1 spectrophotometer. The cDNA was obtained in a thermocycler (Applied Biosystems Veriti ${ }^{\circ}$ Thermal Cycler/US.) by reverse transcription (RT) using $1 \mu \mathrm{g}$ of total RNA from each sample per reaction, with random primers for High-Capacity cDNA Reverse Transcription Kits (Invitrogen no. 4375575), in a final volume of $20 \mu$ l. Reverse transcription was performed in a single cycle, which included: i) $10 \mathrm{~min}$ at $25{ }^{\circ} \mathrm{C}$; ii) $120 \mathrm{~min}$ at $37^{\circ} \mathrm{C}$; iii) $5 \mathrm{~s}$ at $85^{\circ} \mathrm{C}$; and, iv) cooling at $4{ }^{\circ} \mathrm{C}$. The obtained cDNA samples were stored at $-20^{\circ} \mathrm{C}$ until the experiment. PCR was performed using FAST SYBR Green PCR Master Mix (Applied Biosystems, Foster City, CA) in QuantStudio ${ }^{\text {Tu }} 12 \mathrm{~K}$ Flex real-time PCR (Applied Biosystems) with primers designed based on GenBank's database. The mRNA expression of the following genes was determined: RPL27 (NM 000988.3), Foward: CCG AAA TGG GCA AGT TCA T, Reverse: CCA TCA TCA ATG TTC TTC ACG A; SMAD3 (NM_005902.3) Forward: CTA CAG CCA TTC CAT CCC CG, Reverse: AGG TTT GGA GAA CCT GCG TC; SMAD4 (NM_005359.5), Foward: CAC AAG TCA GCC TGC CAG TAT, Reverse: AAT CCA TTC TGC TGC TGT CC; S100A4 (NM_002961.2), Forward: TCT TGG TTT GAT CCT GAC TGCT, Reverse: GTC CTT TCC CCC AAG AAG CTG. Target gene expression was normalized to the reference gene RPL27. The data were analyzed with the 2- $\Delta \Delta C T$ method [2] and expressed as ratio of gene expression normalized to the control sample.

\section{Histological analysis}

Subcutaneous adipose tissue samples (50-100 mg) were obtained after carefully excision with a scalpel blade and fixed in $4 \%$ paraformaldehyde (w/v) in $\mathrm{pH} 4.7$ Phosphate buffer, followed by dehydration in absolute ethanol, diaphanization in xylene and embedding in paraffin (Paraplast X-TRA, SIGMA-ALDRICH). The $5 \mu \mathrm{m} \mathrm{sec-}$ tions were mounted onto slides (Starfrost ${ }^{\circ}$ Knittel Glass). Deparaffinized and hydrated sections were stained with hematoxylin and counterstained with eosin $(n=05$ for all study groups) and photographed under light microscopy (Olympus).

\section{Immunohistochemistry}

Deparaffinized sections $(5 \mu \mathrm{m})$ of subcutaneous adipose tissue were kept at the incubator $37{ }^{\circ} \mathrm{C}$ overnight, before the immunohistochemistry protocol was performed. Subsequently, the slides were hydrated with $0.05 \mathrm{M}$ PBS, at room temperature. Antigen retrieval was carried out in $10 \mathrm{mM}$ of Citrate buffer (pH 6.0) or Tris-EDTA buffer (pH 9.0) at $95{ }^{\circ} \mathrm{C}$ for $20 \mathrm{~min}$. The activity of endogenous peroxidase was blocked in methanol with $0.3 \% \mathrm{H}_{2} \mathrm{O}_{2}$, under light protection. All reactions were performed employing Histostain-Plus, IHC kit, HRP broad spectrum ${ }^{\circ}$ (Life Technologies), following the manufacturer's instructions. After adding the blocking substrate included the kit, sections were incubated overnight $\left(4{ }^{\circ} \mathrm{C}\right)$ with primary antibodies: Anti-Collagen I rabbit monoclonal antibody [EPR7785] (1:100, Abcam), Anti-Collagen type III rabbit polyclonal antibody (1:100, Rockland Immunochemicals Inc), Anti-Collagen type VI rabbit polyclonal antibody (1:40, Millipore), Anti-Human Fibronectin mouse monoclonal antibody (1:50, Millipore), $\alpha$ SMA (1:100, Abcam), TGF $\beta 1$ (V) rabbit polyclonal antibody (1:50, Santa Cruz Biotechnology) and Smad4 (B-8) mouse monoclonal antibody (1:100, Santa Cruz Biotechnology) in a humidified chamber. Negative controls were obtained omitting the primary antibody. Peroxidase activity was revealed with ImmPACT $^{\text {ma }}$ DAB substrate (Vector Laboratories, Burlingame, CA USA) and tissue sections were counterstained with Mayer's hematoxylin ( $n=05$ for all study groups).

In each sample, the immunolabeled tissue was observed under a light microscope (Olympus). Representative images were acquired using Image ProPlus v.5.2 software (Media Cybernetics, Bethesda, MD, USA).

\section{Immunofluorescence}

After the previously described antigen retrieval procedure and quenched endogenous peroxidase activity, sections of subcutaneous adipose tissue were washed with $0.05 \mathrm{M}$ PBS. The blockage of nonspecific sites was performed with normal goat serum, 10\% (Reference: 50197Z Life Technologies, Thermo Scientific, USA) added to $1 \%$ albumin in $0.1 \mathrm{M}$ PBS containing $0.2 \%$ 
Triton X- 100 for $1 \mathrm{~h}$, at room temperature. The antibody Smad3 (86 F7) Rabbit mAb (1:50, Reference: \# 3122, Cell Signaling) was incubated in a humidified chamber, overnight. After removal of the antibody, the sections were washed with $0.1 \mathrm{M} \mathrm{PBS} / 0.2 \%$ Triton X-100 for $5 \mathrm{~min}$. The secondary antibody goat anti-rabbit Alexa 546 (Thermo Scientific, USA) was added for $1 \mathrm{~h}$, protected from light. The slides were mounted using ProLong ${ }^{\oplus}$ Montant Gold Antifade with DAPI (Molecular Probes, Life Technologies, USA).

\section{Statistical analysis}

Data were expressed as the median [1st, quartile; 3rd, quartile]. The difference between the groups was assessed by Kruskal-Wallis followed by Dunn post-test, as data presented a non-parametric distribution. Data for group classification and characterization were expressed as mean \pm standard error. In this case, one-way analysis of variance with Tukey post-test was adopted. Differences were considered as statistically significant for $P<0.05$. The statistical data analysis was carried out with the statistical package software GraphPad PRISM (GraphPad Prism version 5.00 for Windows, GraphPad Software, San Diego California USA, www.graphpad.com"). All statistical procedures were performed with the assistance of the Statistics Sector of the Institute of Biomedical Sciences, USP, under the supervision of Ms. Rosana Prisco.

\section{Results}

\section{General and clinical characteristics of study groups}

The clinical characteristics of patients distributed in the study groups are shown in Table 1. For all groups, similar height and age were found. Current and previous weights for 6-12 months (before inclusion of patients in the study), as reported by patients, did not present significant differences among the groups. As expected, the cancer cachexia group $(\mathrm{CC})$ exhibited a pronounced weight loss with $14 \%$ body mass reduction $(-8.0[-12.50 ;-7.0])$, while the weight-stable cancer group (WSC) showed body mass variation less than $4.2 \%$, and no changes were observed for the control group (C). Similar results for BMI index were found for all groups.

In order to assess the biochemical values of the parameters employed to determine the patients clinical condition, we examined the serum levels of C-Reactive Protein, albumin, hemoglobin and the plasma levels of interleukin 6 (IL-6) and TNF alpha (TNF $\alpha$ ). The C-Reactive Protein values were increased in CC (4.95-fold and 3.05-fold as compared with $\mathrm{C}$ and WSC groups, respectively). Hemoglobin and albumin were significantly reduced in $\mathrm{CC}$, in comparison to the control. Despite the consensus recommendation of albumin levels being around $3.2 \mathrm{~g} / \mathrm{dL}$, for cachexia diagnosis, CC showed a variation from 2.79 to $4.58 \mathrm{~g} / \mathrm{dL}$. In addition, the plasma levels of IL6 (pg/ml) were elevated in cachexia $(4.10 \mathrm{pg} / \mathrm{ml})$, whereas, detection in the control $(0.00[0.00 ; 0.84] \mathrm{pg} / \mathrm{ml})$ and WSC $(0.62[0.00 ; 1.77] \mathrm{pg} / \mathrm{ml})$ were low. TNF $\alpha$ levels were also enhanced in cachexia $(p<0.02)$, but only compared with the control group. The results show higher systemic inflammation in cachectic patients represented by higher plasma levels of CRP, IL6 and TNF $\alpha$.

Other plasma pro-inflammatory cytokines were assessed, as shown in Table 1: interleukin (IL) 2(IL2), IL5, IL8, IL3, IL17. All of which have been linked to the development of fibrosis in several experimental models and diseases [29, 31, 37-39]. There was no detection of IL2 values in the plasma of any of the groups. For IL13 and IL17, the levels were not statistically different among the groups. The enhanced expression of IL5 has been associated with elevated levels of IL13 or IL17 [37-40]. Despite these cytokines not presenting any difference induced by cachexia or cancer, when compared with the control group, the levels of IL5 were found to be increased in CC $(p<0.02)$. CC showed higher values of IL8, (55-fold), (28.91 $\mathrm{pg} / \mathrm{ml})$, compared with the control $(0.52 \mathrm{pg} / \mathrm{ml})$, and with WSC $(4.79 \mathrm{pg} / \mathrm{ml})$. Thus, the differences of inflammatory and pro-inflammatory cytokines were more pronounced in the cachectic patients and can be interpreted as indicative of local inflammation.

\section{Extracellular matrix proteins are overexpressed in the subcutaneous adipose tissue of cancer cachexia}

Consistent with our previous findings [35], morphological analysis under light microscopy carried out in haematoxylin and eosin stained sections showed deep modifications in the subcutaneous adipose tissue, exclusively in CC, with differences in the shape of adipocytes and augmented interstitial space (Fig. 1a). The presence of areas with collagen deposits was also more intense in CC compared with control and WSC (Fig. 1b). Along with collagen deposition, we observed an accumulation of mature elastic fibers only in CC (Fig. 1c).

To characterize the presence of fibrosis in the subcutaneous AT, we investigated by immunohistochemistry, the presence of different types of collagen: type I (COL1), type III (COL3) and type VI (COL6), and of fibronectin (FN). As shown in Fig. 2a, b, c and d respectively, we found similar labeling for COL1, COL3, COL6 and FN for WSC and for the control group. COL6 expression was more evident surrounding adipocytes in all groups than that of COL1 and COL3. The differences were even more pronounced when staining for COL1, COL3, COL6 and FN in the AT of the CC group. In fact, we detected the presence of fibrotic areas in $\mathrm{CC}$, with an accumulation of all the studied collagens along with increased fibronectin expression. In the sections labeled for FN, we observed deposition of fibronectin exclusively in the fibrotic areas. 


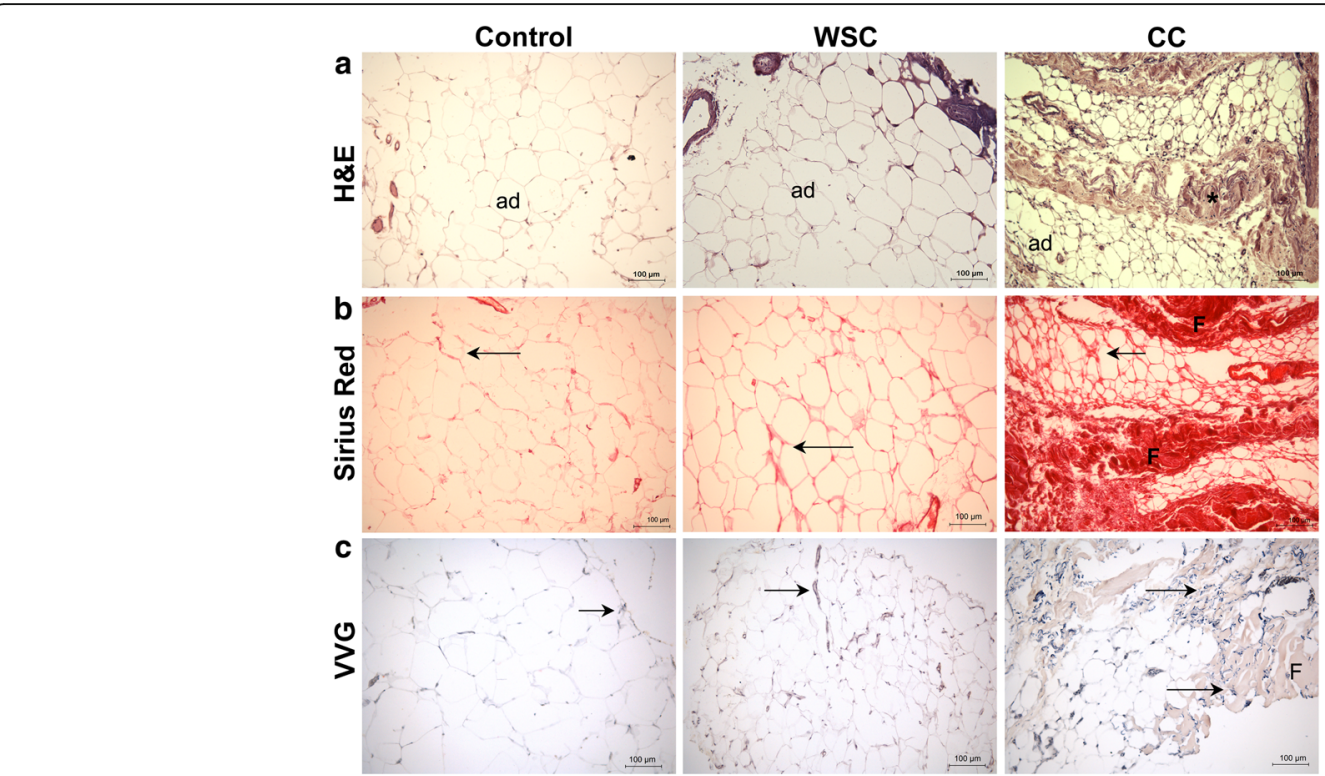

Fig. 1 Adipose tissue remodeling is triggered during cancer cachexia. a Haematoxilin and eosin sections of subcutaneous adipose tissue. b Collagen detection by Picro Sirius Red staining. c Localization of elastic fibers performed with Verhoeff's Van Gieson staining. Photomicrographs of the representative images from each group: Control $(n=5)$, Weight-stable cancer (WSC; $n=5)$, Cancer cachexia (CC; $n=5)$. Ad- Illustrates preserved adipocytes. Arrows indicate intense labeling. F- Indicates areas with excessive ECM deposition (fibrotic areas)

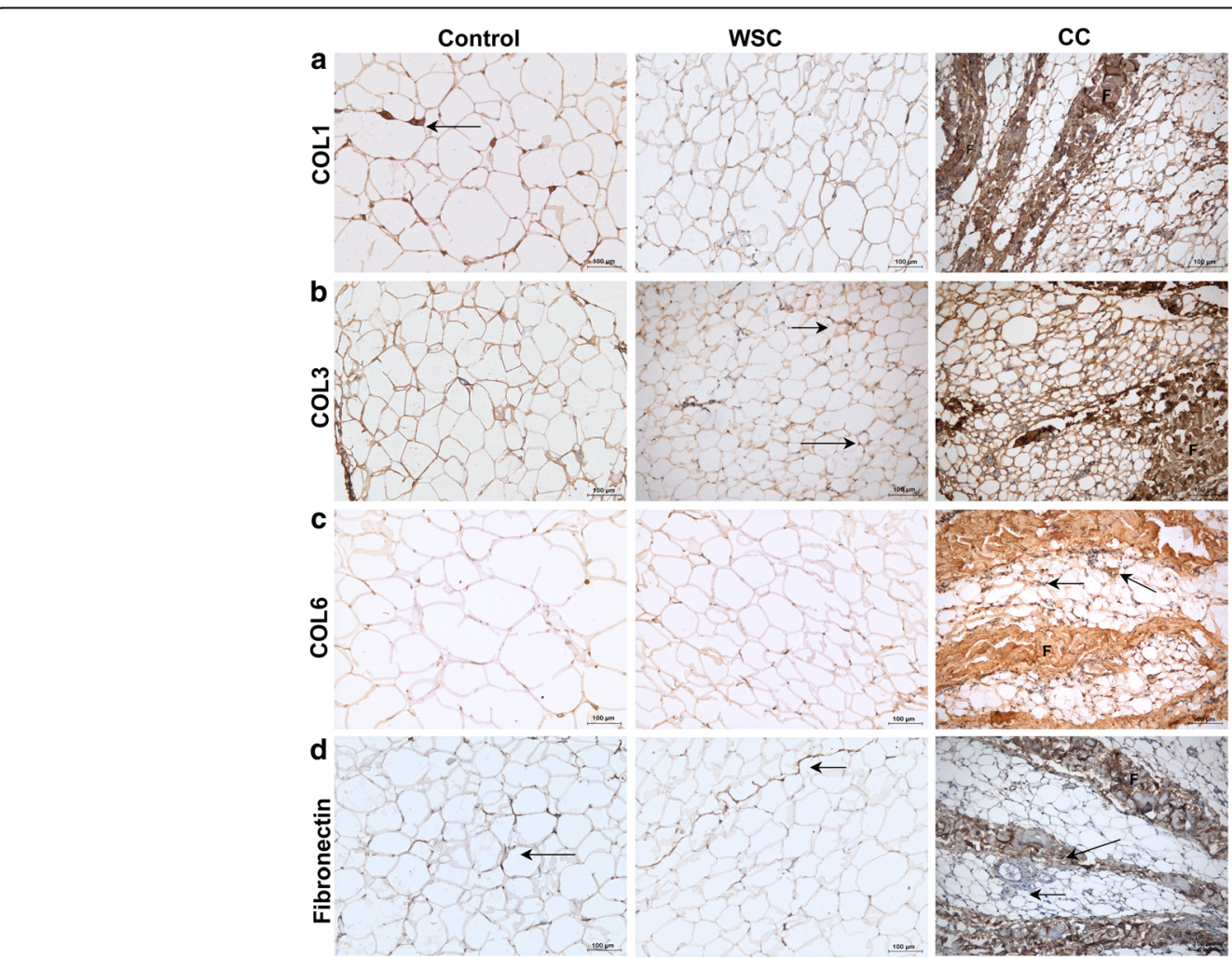

Fig. 2 Cachexia induces overexpression of collagen type I, III, VI and fibronectin in the adipose tissue. a-d Sections of human subcutaneous adipose tissue were immunostained with (a) COL1A1, (b) COL3A1, (c) COL6A1, and (d) Fibronectin (FN1). Control ( $n=5$ ), Weight-stable cancer (WSC; $n=5)$, Cancer cachexia (CC; $n=5)$. Note the positive labeling for all groups, with stronger intensity in CC. Immunostaining for COL6A1 in Control, WSC and CC samples was found around the adipocytes, whereas, in CC, positive staining in several fibrotic areas were observed (F). Ad- Illustrates preserved adipocytes. Blue staining (Mayer's Haematoxylin) represents a non-reactive nucleous 
The overexpression of ECM proteins shown by our results illustrates not only AT remodeling, but the emergence of fibrosis in the AT, due to cancer cachexia.

\section{Myofibroblasts contributing to fibrosis of adipose tissue in cancer cachexia}

In order to assess the contribution of fibroblasts with an activated phenotype, myofibroblasts, to the excessive deposition of ECM components in cancer cachexia, we measured $\alpha$-smooth muscle actin ( $\alpha$ SMA) expression. Our results demonstrate (Fig. 3a), as expected, higher expression of $\alpha \mathrm{SMA}$, restricted to vessels walls in sections of WSC when compared to the control group and CC. Interestingly, the presence of myofibroblasts was often found in AT of cachectic patients, specially surrounding adipocytes. The gene expression of the fibroblast-specific protein (FSP1) (also called S100A4) was similarly evaluated. As shown in Fig. 3d, there was a 20-fold increase of FSP1 mRNA levels in CC, compared to controls $(p<0.05)$. Thus, this confirms the presence of activated myofibroblasts with enhanced ECM proteins synthesis due to cachexia.

\section{TGF $\beta$ pathway up-regulated by cachexia}

The TGF $\beta$ signaling pathway can directly induce myofibroblasts to produce ECM components. To assess the role of TGF $\beta$ in ECM remodeling in adipose tissue during cachexia, we detected TGF $\beta$ and SMADs proteins expression by different approaches. Immunohistochemistry analysis under light microscopy revealed that there was marked TGF $\beta 1$ expression in representative sections from CC group in relation to $\mathrm{C}$ and WSC (Fig. 3a). We observed TGF $\beta 1$ labeling surrounding each adipocyte, and between the fibrotic areas in the AT from cachectic patients.

Smads are proteins which act as downstream signals of the TGF $\beta$ pathway. Smad4 interacts with Smad2 and Smad3, forming a complex which rapidly translocates into the nucleus and binds to DNA [26, 41-43]. Firstly, we detected immunolabeling of Smad4 (Fig. 3c) in the AT which was solely present in $\mathrm{CC}$, especially within the fibrotic areas. We analyzed the mRNA levels of Smad3 and Smad4 in the AT (Fig. 3e-f). No differences for gene expression of Smad3 were found, whereas there were increased mRNA levels for Smad4 in WSC and CC groups, both in comparison to the control $(p<0.003)$. The immunofluorescence of Smad3 (Fig. 4g) also

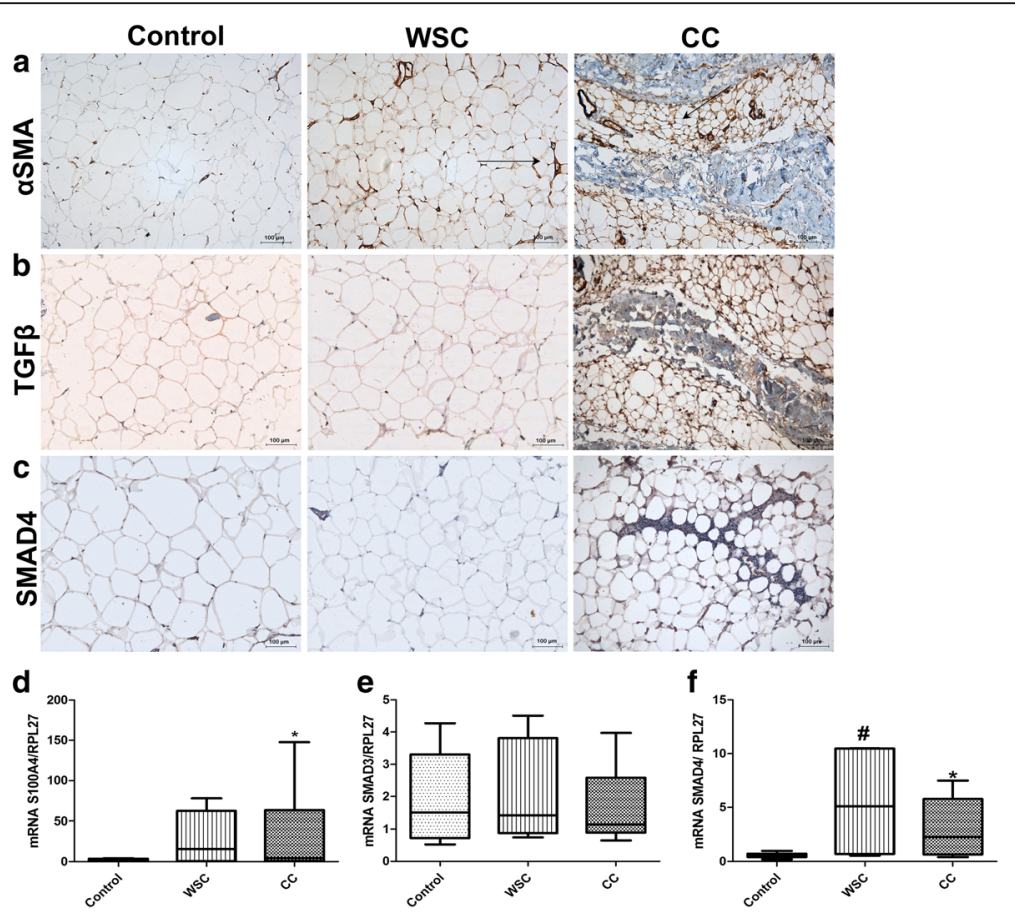

Fig. 3 TGF $\beta$ and Myofibroblast presence contributes to adipose tissue fibrosis in cancer cachexia. a Immunohistochemistry for myofibroblasts with aSMA antibody. Note that almost immunoreactivity in WSC is in vessel walls, whereas CC shows positive cells among adipocytes and in (F) fibrotic areas. b-c TGF $\beta$ immunohistochemical analysis in subcutaneous AT illustrates its possible role in inducing cachexia-associated fibrosis, whereas (c) Smad4 shows activation of this pathway. Counterstaining (blue) with Mayer's Haematoxylin was performed. The groups were identified as Control $(n=5)$, Weight-stable cancer (WSC; $n=5)$, Cancer cachexia (CC; $n=5)$. Fibrotic areas are indicated (F). Arrows indicate positive labeling. $\mathbf{d}-\mathbf{f} \mathbf{q P C R}$ analysis of fibroblast marker (d) FSP1 (S100A4) (control, $n=13$; WSC $n=6$; CC $n=12$ ), (e) Smad3 (control, $n=9$; WSC $n=6$; CC $n=7$ ), and (f) Smad4 (control, $n=11$; WSC $n=7$; CC $n=12$ ). Data presented as median and 1st and 3st quartile. ${ }^{*} p<0.05$ CC vs control; \# WSC vs control 

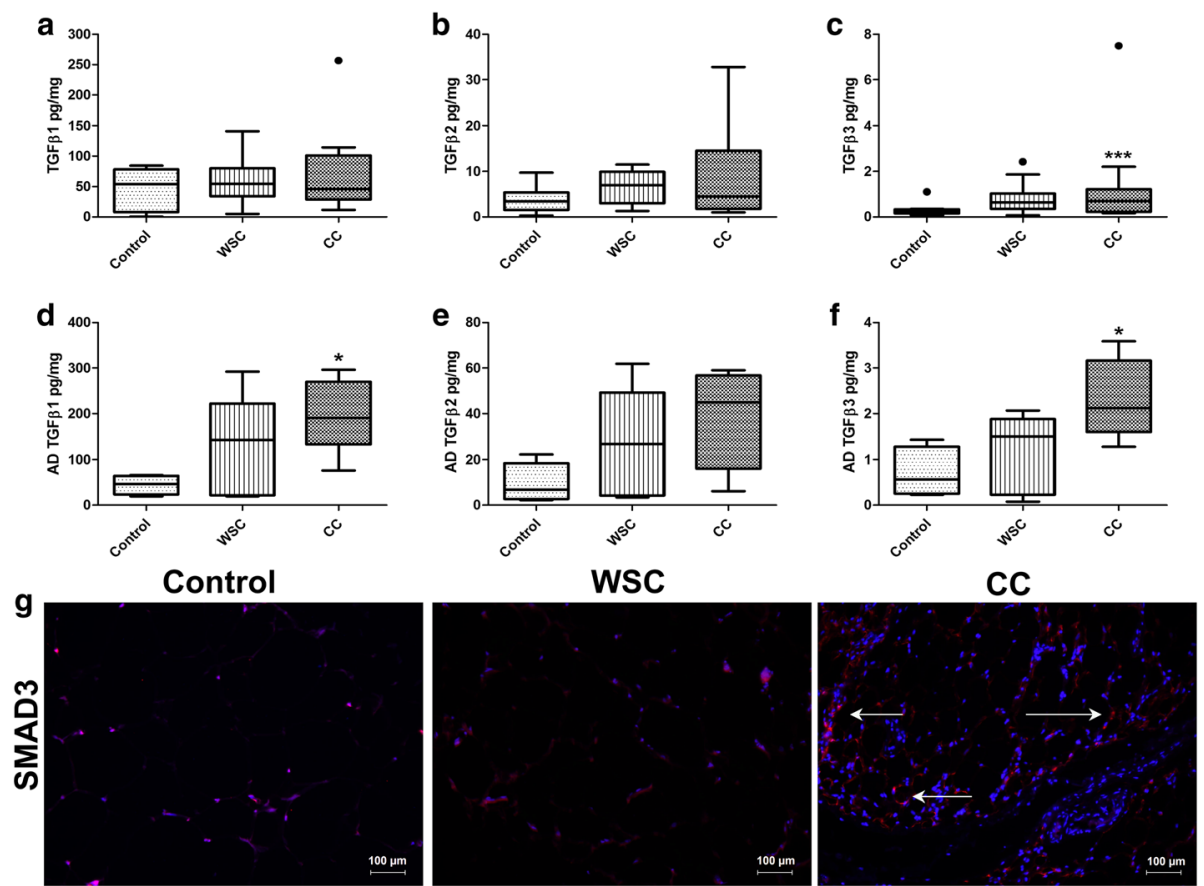

Fig. 4 TGF $\beta$ pathway is activated in the fibrotic subcutaneous AT in cancer cachexia. a-c Multiplex assay analysis of activated (a) TGF $\beta 1$, (b) TGF $\beta 2$, and (c) TGF $\beta 3$ in whole subcutaneous AT. Control $(n=14)$, Weight-stable cancer (WSC) $(n=12)$, Cancer cachexia (CC) $(n=14)$. d-f Adipocytes also contribute for the enhanced observed TGF $\beta$ levels, as shown by Multiplex analysis of (a) TGF $\beta 1$, (b) TGF $\beta 2$, and (c) TGF $\beta 3$ from isolated adipocytes of subcutaneous AT. Control $(n=5)$, Weight-stable cancer (WSC) $(n=5)$, Cancer cachexia (CC) $(n=5)$. Data presented as median and 1st and 3 st quartile. ${ }^{*} p<0.05$, CC vs control; ${ }^{* * *} p<0.003$ CC vs control. g Immunofluorescence staining in subcutaneous AT for Smad3 (red) and DAPI (blue) for nuclei, which showed higher density for Smad3 labeling in cancer cachexia. Control $(n=5)$, Weight-stable cancer (WSC; $n=5)$, Cancer cachexia $(C C ; n=5)$

demonstrated a more evident expression in CC compared with WSC and the control.

To further explore these results, we quantified the content of the activated isoforms TGF $\beta 1$, TGF $\beta 2$ and TGF $\beta 3$ by Multiplex assay. We failed to find a statistical difference for TGF $\beta 1$ levels among the groups $(p=0.6055)$, as shown in Fig. 4a. There were no alterations for isoform $\beta 2$ in the subcutaneous AT (Fig. 4b). Our results show an increased concentration of TGF $\beta 3$ in CC, compared with the controls $(p=0.03)$. In adipocytes isolated from the subcutaneous adipose tissue, (results presented in Fig. 4d-f) an enhanced protein expression of TGF $\beta 1$ and TGF $\beta 3$ in cachectic patients in relation to the control group $(p<0.05)$ was found. There was a rise of 4-fold and 3.4-fold for TGF $\beta 1$ and TGF $\beta 3$ concentrations, respectively, in the adipocytes of $\mathrm{CC}$. These results demonstrate that there is a contribution of adipocytes to fibrosis in AT.

Taken together, our findings indicate that there is an augmented activation of the TGF $\beta$ pathway in the AT of cachectic patients, revealing an active role of this pathway for disrupted biology tissue and consequent fibrosis.

\section{Discussion}

Cachexia is a wasting disease which affects approximately nine million people worldwide [44]. Cancer cachexia is characterized by progressive body weight reduction due to the loss of skeletal muscle and adipose tissue often associated with systemic inflammation. Current knowledge has shown that adipose tissue depletion in cancer cachexia results from body composition alterations concerning impaired lipid storage capacity and increased lipolysis ratio [13]. We previously showed that the AT suffers morphological modifications which reflects in the reduction of adipocyte size and ECM remodeling in cancer cachexia [35].

Our present findings demonstrate that ECM remodeling of AT in cachexia results not only in augmented collagen fiber content, but also, in excessive elastic fibers and fibronectin deposition. The presence of fibrosis was associated with an increased number of myofibroblasts and an activated TGF $\beta / S M A D$ pathway in the subcutaneous AT of gastrointestinal cancer cachectic patients.

In animal models for cancer cachexia (MAC16 tumor bearing-mice) shrunken adipocytes and increased collagen-fibril content in WAT were reported [9]. AT is embedded in a thick ECM surrounding each adipocyte. Nakajima et al. [45] described the presence of type I-VI collagens, laminin and fibronectin in differentiated bovine pre-adipocytes (BIP). Our data show that collagen deposition is accompanied by excessive synthesis of mature elastic fibers, compromising the microenvironment 
of adipose tissue due to cachexia. We also explored each collagen isoform modified by cachexia. There was strong labeling for collagen type I (COL1) and III (COL3) in the AT from cachectic patients, without differences for control and weight-stable cancer patients, indicating the contribution of both types of collagens for disruption of adipose tissue. Studies with obese subjects reported the presence of fibrous bands in the AT, accessed by Sirius Red staining, whereas in lean individuals, the content of collagen was not changed. In addition, increased amounts of collagen VI (COL6) were found in obese rather than in lean subjects [19].

The expression of COL6 seems to be more specific for adipose tissue since it exhibited a higher expression among different depots of fat, in comparison with liver, muscle, heart, and pancreas, in normal conditions, whereas, the absence of COL6 resulted in an uninhibited expansion of adipocytes [20]. High levels of COL6 in the AT are directly associated with inflammation and fibrosis in obese individuals and in animal models. In obese subjects, immunohistochemistry analysis revealed a stronger label for COL6 and increased mRNA levels of subunit alpha 1 (COL6A1), and both were highly correlated with CTGF and TGF $\beta$ levels [46]. The subunit alpha 3 of collagen VI (COL6A3) was also found increased in diabetic obese animals, as well as in obese subjects, with a positive correlation between increased visceral adipose tissue mass and inflammation, independent of BMI; whereas the expression in the subcutaneous AT remained unchanged $[20,47]$. The complete assembly of all three chain subunits; $\alpha 1$ (COL1A1), $\alpha 2$ (COL6A2) and $\alpha 3$ (COL6A3) is necessary for stable formation and functionality of COL6 [48]. In this study, we demonstrate the positive presence of COL6A1 in the subcutaneous AT of non-cachectic patients. However, there was a higher expression of COL6A1 in the samples of cachectic patients, accompanied by the presence of intensely labeled bundles in CC.

We report that all of the studied collagen types (COL1A1, COL3A1, and COL6A1) in the AT, to be modulated by cancer cachexia. Fibronectin (FN) has been reported to be found in colocalization with collagen fibers from secretory fibroblasts, while FN absence impairs collagen assembly [49]. The observed changes in collagen deposition dysregulated by cachexia are, in fact, accompanied by augmented FN in the AT of CC. The fibrotic areas were also positively labeled for FN in CC. In studies with obese patients, a strong staining for FN was found in fibrotic regions, the presence of which was increased in the serial sections of AT [50]. Our data demonstrate which ECM proteins induce alterations in the morphology of fat tissue promoting the emergence of fibrosis, in association with cancer cachexia.

Cancer cachexia is orchestrated, in part, by a network of inflammatory factors that are activated for signaling pathways from each tissue joining tumor-derived factors that are the result of malignant inflammation [6]. Consistent with international consensus for cachexia diagnosis, our results demonstrate systemic inflammation in cancer cachectic vs. non-cachectic patients, with increased circulating CRP, IL6, TNF $\alpha$, IL8, and IL5 levels. A previous study reported that high plasma concentrations of IL8 in patients with advanced lung cancer (stage IV), were correlated with cachexia [51]. On the other hand, increased circulating levels of IL8 are also reported as markers in patients with pulmonary fibrosis [52]. The expression of IL13 and IL17 cytokines has an important role in tissue remodeling and fibrosis. IL13 acts directly to induce collagen production in fibroblasts, thus stimulating proinflammatory mediators, macrophages and dendritic cells [37, 53]. IL17 produced by Th17 cells contributes to the innate and adaptive immune responses, as well to the perpetuation of inflammation with neutrophilia, which in turn, induces tissue damage and fibrosis [38]. In addition, IL17 expression is correlated in the pathogenesis of pulmonary fibrosis, myocardial fibrosis and hepatic fibrosis [38]. Despite this, our study did not presented high levels of IL13 or IL17, whereas, the IL5 expression was significantly enhanced in the plasma from cachectic patients. In the liver fibrosis, the increased levels of IL5 lead to progress of tissue damage by regulating IL13 production and macrophage activation [39]. During states of chronic inflammation, the presence of infiltrating macrophages can augment the myofibroblast activation, tissue damage and fibrosis $[23,53,54]$.

Myofibroblasts are contractile cells overexpressing $\alpha$ SMA and specialize in synthesizing ECM proteins in wound healing responses [23, 29]. $\alpha$-SMA expression has a critical role in cell motility and contractility during tissue repair, but is also associated to the induction of a fibrotic state [34]. A 3 T3 cell lineage of fibroblasts transfected with $\alpha$-SMA resulted in cell contractility, which is doubled in lung fibroblasts expressing high levels of $\alpha$-SMA via TGF $\beta 1$ pathway [30]. Mechanical stress caused by excessive contractility leads to an aberrant wound-healing response and fibrosis [33]. In epithelial-mesenchymal cell transition (EMT), which occurs in pulmonary fibrosis, is seen the concomitant increased amounts of mRNA levels of $\alpha$-SMA, FSP1 and vimentin [55]. According with this, our study showed enhanced immunolabeling of $\alpha$-SMA in the subcutaneous AT of cancer cachectic group, as well as increased mRNA expression of FSP1. Taken together, these results reveal that changes in collagen and fibronectin expression are associated with increased amounts of activated fibroblasts in cachexia.

TGF $\beta$, a multifunctional cytokine, presents antiinflammatory and pro-fibrotic activity. This dual role 
leads to different responses in multiples biological pathways depending of context for their action $[23,56]$. TGF $\beta$ expression is robustly correlated with the development of fibrosis in the liver, lung, kidney, skin and in cardiac tissues under pathological conditions [23]. In WAT, increased expression of TGF $\beta$ has also been reported in obese mice $(\mathrm{ob} / \mathrm{ob})[57,58]$ and in human subjects $[59,60]$. In the AT from obese patients and/or rodents, fibrotic areas are frequent $[9,61]$. Interestingly, TGF $\beta 1$ was increased in subcutaneous AT from cancer cachectic patients, and it was up-regulated in the whole tissue samples, as well as in the isolated adipocytes. The TGF 33 isoform was elevated solely in the adipocytes, demonstrating the contribution of these cells to the fibrotic state of the AT. The three isoforms: TGF $\beta 1$, TGF $\beta 2$, and TGF $\beta 3$, most expressed in mammals, induce different biological effects. The TGF $\beta 1$ isoform seems to play a more important role in wound response and fibrosis [28].

The Smads are a family of transcriptional activators triggered in response to TGF $\beta$. Heterocomplexes formed by $\mathrm{R}-\mathrm{Smad}(\mathrm{Smad} 2 / \mathrm{Smad} 3)$ with $\mathrm{Smad} 4$ are required to bind DNA regulating gene expression [24]. In knockout models for Smad3, accelerated wound-healing response with low inflammation is demonstrated [24]. TGF $\beta$ signaling pathway inhibition has been shown to reduce the development of fibrosis in experimental models [23]. On the other hand, in obesity, expansion of adipocytes is associated with tissue remodeling and fibrosis. The expression of Smad3 is also enhanced in ob/ob mice in fat depots and Smad3 inhibition in vitro results in deficient adipocyte differentiation [57].

Our main interest was to investigate the relationship among adipose tissue fibrosis in cachectic cancer patients and activation of the TGF $\beta$ canonical pathway. TGF $\beta$ is a cytokine able to activate a wide array of additional cellular functions through non-canonical pathways, such as Rho-like GTPase signaling [62]. In cultured adipocytes, an enhanced Rho-Rho-kinase signaling results in activation of NF- $\mathrm{KB}$ and TNFo [63]. In vivo, the inflammatory changes induced by Rho-Rho-kinase signaling, contribute to deregulated adipocytokine expression and recruitment of inflammatory cells to the adipose tissue, which in turn, exacerbates the inflammatory scenario described in obesity [64]. The activation of Rho-kinase by Rho, in addition to Smads signaling triggered by TGF $\beta$ in the adipose tissue of cachectic patients could lead to the aggravation of inflammation and, consequently, to fibrosis, but, a detailed study investigating the multiple mechanisms activated by Rho-Rho-kinase during cachexia is necessary.

The subcutaneous AT of cachectic patients show activation of the TGF $\beta$ pathway via Smads. We report herein, an increased expression of TGF $\beta$ occurs in parallel with Smad3 and 4, thus, demonstrating there was a cytoplasmatic translocation of the Smad complex to the nucleus. Considering this, we suggest that TGF $\beta / \mathrm{Smad}$ signaling contributes to remodeling, and consequently to fibrosis of AT in cancer cachexia. We speculate that the fibrotic response of AT during cachexia may be triggered by systemic inflammation, concomitant with the activation myofibroblasts contributing to ECM deposition and tissue contractility, through TGF $\beta /$ Smad signaling.

\section{Conclusions}

Our study shows the presence of fibrosis in the subcutaneous adipose tissue due to cachexia. In this process, the TGF $\beta$ canonic pathway seems to play an important role. The re-arrangement of adipose tissue in cachexia includes elastic fibers, collagens -especially type I, III, VI- and fibronectin. Additionally, the presence of myofibroblasts surrounding adipocytes along with the increased pro-inflammatory cytokine content, indicate severe tissue damage. Extracellular matrix components are crucial for adipose tissue biology. In fact, uncontrolled deposition of collagens, and of other ECM proteins, can prevent the expansion of adipocytes thus leading to the failure of treatments aiming at recovering adipose tissue wasting in cachectic patients.

\section{Abbreviations \\ AT: Adipose tissue; CC: Cancer cachexia; ECM: Extracellular matrix; FN: Fibronectin; FSP1: Fibroblast-specific protein; IL: Interleukin; \\ TGF $\beta$ : Transforming growth factor beta; WAT: White adipose tissue; WSC: Weight-stable cancer; aSMA: Alpha-smooth muscle actin}

\section{Acknowledgments}

We thank all members of Cancer Metabolism group for discussions, in particular, Emilia Ribeiro for excellent technical assistance. The clinical and surgical work was performed at the University Hospital and we are grateful for all technical and staff support.

\section{Funding}

This work was supported mainly by São Paulo Research Foundation (FAPESP; 2012/50079-0) and CAPES. The contents of this work are solely the responsibility of the authors and do not necessarily represent the official views of FAPESP.

Availability of data and materials

Data are available on request to the authors.

\section{Authors' contributions}

MJA with MS conceptualized the study. MJA drafted the initial manuscript. Immunohistochemistry experiments and morphological analysis were performed together with FAF, RGF and DAC. Multiplex cytokines assay experiments were performed by: MJA, EMN, DMR and KR, whereas MJA, NIPN, RGF and JDCL carried out TGF $\beta$ Multiplex Assay. RGC, PSMA, JPO, MBJ contributed to the patient recruitment, interviews, as well, all authors contributed to the tissue and blood collection, and data analysis. All authors read and approved the final manuscript.

Competing interests

The authors declare that they have no competing interests.

Consent for publication

Not applicable. 


\section{Ethics approval and consent to participate}

All proceedings were performed in agreement with the Declaration of Helsinki and approved by the Ethics Committee on Research Involving Human Subjects of the Institute of Biomedical Sciences/University of Sao Paulo (1082/CEP) and by the Human Ethics Committee of the University Hospital/University of Sao Paulo (CEP 752/07). The acceptance for study participation and, data publication was obtained by written consent after the detailed explanation

\section{Publisher's Note}

Springer Nature remains neutral with regard to jurisdictional claims in published maps and institutional affiliations.

\begin{abstract}
Author details
${ }^{1}$ Cancer Metabolism Research Group, Institute of Biomedical Sciences, University of Sao Paulo, Sao Paulo, Brazil. ²Department of Surgery, Faculty of Medicine, University of Sao Paulo, Sao Paulo, Brazil. ${ }^{3}$ Department of Clinical Surgery, Hospital University, University of Sao Paulo, Sao Paulo, Brazil. ${ }^{4}$ Biotechnology Group, Laboratory of Adipose Tissue Biology, University of Mogi das Cruzes, Mogi das Cruzes, Brazil. ${ }^{5}$ Department of Nutrition, Federal University of Sao Paulo, Sao Paulo, Brazil. ${ }^{6}$ Faculty of Nursing, University of Campinas, Campinas, Brazil.
\end{abstract}

\section{Received: 1 November 2016 Accepted: 8 March 2017}

Published online: 14 March 2017

\section{References}

1. Evans WJ, Morley JE, Argilés J, Bales C, Baracos V, Guttridge D, Jatoi A, Kalantar-Zadeh K, Lochs H, Mantovani G, et al. Cachexia: a new definition. Clin Nutr. 2008;27(6):793-9.

2. Letilovic T, Vrhovac R. Influence of additional criteria from a definition of cachexia on its prevalence-good or bad thing? Eur J Clin Nutr. 2013;67(8):797-801.

3. Fearon K, Strasser F, Anker SD, Bosaeus I, Bruera E, Fainsinger RL, Jatoi A, Loprinzi C, MacDonald N, Mantovani G, et al. Definition and classification of cancer cachexia: an international consensus. Lancet Oncol. 2011:12(5):489-95.

4. Tisdale MJ. Cancer cachexia. Curr Opin Gastroenterol. 2010;26(2):146-51.

5. Argilés JM, Stemmler B, López-Soriano FJ, Busquets S. Nonmuscle tissues contribution to cancer cachexia. Mediators Inflamm. 2015;2015:182872.

6. Tsoli M, Robertson G. Cancer cachexia: malignant inflammation, tumorkines, and metabolic mayhem. Trends Endocrinol Metab. 2013;24(4):174-83.

7. Muscaritoli M, Molfino A, Gioia G, Laviano A, Rossi Fanelli F. The "parallel pathway": a novel nutritional and metabolic approach to cancer patients. Intern Emerg Med. 2011;6(2):105-12.

8. Argilés JM, Busquets S, Stemmler B, López-Soriano FJ. Cancer cachexia: understanding the molecular basis. Nat Rev Cancer. 2014;14(11):754-62.

9. Bing C, Russell S, Becket E, Pope M, Tisdale MJ, Trayhurn P, Jenkins JR. Adipose atrophy in cancer cachexia: morphologic and molecular analysis of adipose tissue in tumour-bearing mice. Br J Cancer. 2006;95(8):1028-37.

10. Ouchi N, Parker JL, Lugus JJ, Walsh K. Adipokines in inflammation and metabolic disease. Nat Rev Immunol. 2011;11(2):85-97.

11. Trayhurn P. Adipocyte biology. Obes Rev. 2007:8 Suppl 1:41-4.

12. Jensen J, Trayhurn P, Handberg A, Eckel J. Adipose tissue. Editorial. Arch Physiol Biochem. 2011;117(2):45-6.

13. Ebadi M, Mazurak VC. Potential biomarkers of fat loss as a feature of cancer cachexia. Mediators Inflamm. 2015;2015:820934.

14. Batista ML, Peres SB, McDonald ME, Alcantara PS, Olivan M, Otoch JP, Farmer SR, Seelaender M. Adipose tissue inflammation and cancer cachexia: possible role of nuclear transcription factors. Cytokine. 2012;57(1):9-16.

15. Batista ML, Olivan M, Alcantara PS, Sandoval R, Peres SB, Neves RX Silverio R, Maximiano LF, Otoch JP, Seelaender M. Adipose tissue-derived factors as potential biomarkers in cachectic cancer patients. Cytokine. 2013;61(2):532-9.

16. Camargo RG, Riccardi DM, Ribeiro HQ, Carnevali LC, de Matos-Neto EM, Enjiu L, Neves RX, Lima JD, Figuerêdo RG, de Alcântara PS, et al. NF-kBp65 and expression of its pro-inflammatory target genes are upregulated in the subcutaneous adipose tissue of cachectic cancer patients. Nutrients. 2015;7(6):4465-79.

17. Pond CM. Adipose tissue and the immune system. Prostaglandins Leukot Essent Fatty Acids. 2005;73(1):17-30
18. Mariman EC, Wang P. Adipocyte extracellular matrix composition, dynamics and role in obesity. Cell Mol Life Sci. 2010;67(8):1277-92.

19. Divoux A, Clément K. Architecture and the extracellular matrix: the still unappreciated components of the adipose tissue. Obes Rev. 2011;12(5):e494-503.

20. Khan T, Muise ES, lyengar P, Wang ZV, Chandalia M, Abate N, Zhang BB, Bonaldo P, Chua S, Scherer PE. Metabolic dysregulation and adipose tissue fibrosis: role of collagen VI. Mol Cell Biol. 2009;29(6):1575-91.

21. Ali AT, Hochfeld WE, Myburgh R, Pepper MS. Adipocyte and adipogenesis. Eur J Cell Biol. 2013;92(6-7):229-36.

22. Wynn TA. Common and unique mechanisms regulate fibrosis in various fibroproliferative diseases. J Clin Invest. 2007;117(3):524-9.

23. Wynn TA, Ramalingam TR. Mechanisms of fibrosis: therapeutic translation for fibrotic disease. Nat Med. 2012;18(7):1028-40

24. Leask A, Abraham DJ. TGF-beta signaling and the fibrotic response. FASEB J. 2004;18(7):816-27

25. Massagué J. How cells read TGF-beta signals. Nat Rev Mol Cell Biol. 2000;1(3):169-78.

26. Massagué J, Wotton D. Transcriptional control by the TGF-beta/Smad signaling system. EMBO J. 2000;19(8):1745-54

27. Macias MJ, Martin-Malpartida P, Massagué J. Structural determinants of Smad function in TGF- $\beta$ signaling. Trends Biochem Sci. 2015;40(6):296-308.

28. Flanders KC. Smad3 as a mediator of the fibrotic response. Int J Exp Pathol. 2004:85(2):47-64.

29. Wynn TA. Cellular and molecular mechanisms of fibrosis. J Pathol. 2008;214(2):199-210

30. Hinz B. The extracellular matrix and transforming growth factor- $\beta 1$ : Tale of a strained relationship. Matrix Biol. 2015:47:54-65.

31. Ueha S, Shand FH, Matsushima K. Cellular and molecular mechanisms of chronic inflammation-associated organ fibrosis. Front Immunol. 2012;3:71.

32. Harris WT, Kelly DR, Zhou Y, Wang D, MacEwen M, Macewen M, Hagood JS, Clancy JP, Ambalavanan N, Sorscher EJ. Myofibroblast differentiation and enhanced TGF-B signaling in cystic fibrosis lung disease. PLoS One. 2013:8(8):e70196.

33. Brenner DA, Kisseleva T, Scholten D, Paik YH, Iwaisako K, Inokuchi S, Schnabl B, Seki E, De Minicis S, Oesterreicher C, et al. Origin of myofibroblasts in liver fibrosis. Fibrogenesis Tissue Repair. 2012;5 Suppl 1:S17.

34. Rockey DC, Weymouth N, Shi Z. Smooth muscle a actin (Acta2) and myofibroblast function during hepatic wound healing. PLoS One. 2013:8(10):e77166.

35. Batista ML, Henriques FS, Neves RX, Olivan MR, Matos-Neto EM, Alcântara PS, Maximiano LF, Otoch JP, Alves MJ, Seelaender M. Cachexia-associated adipose tissue morphological rearrangement in gastrointestinal cancer patients. J Cachexia Sarcopenia Muscle. 2016;7(1):37-47.

36. RODBELL M. Metabolism of isolated fat cells. I. Effects of hormones on glucose metabolism and lipolysis. J Biol Chem. 1964;239:375-80.

37. Wynn TA. IL-13 effector functions. Annu Rev Immunol. 2003:21:425-56.

38. Isailovic N, Daigo K, Mantovani A, Selmi C. Interleukin-17 and innate immunity in infections and chronic inflammation. J Autoimmun. 2015;60:1-11.

39. Reiman RM, Thompson RW, Feng CG, Hari D, Knight R, Cheever AW, Rosenberg HF, Wynn TA. Interleukin-5 (IL-5) augments the progression of liver fibrosis by regulating IL-13 activity. Infect Immun. 2006;74(3):1471-9.

40. Sutherland TE, Logan N, Rückerl D, Humbles AA, Allan SM, Papayannopoulos V, Stockinger B, Maizels RM, Allen JE. Chitinase-like proteins promote IL-17-mediated neutrophilia in a tradeoff between nematode killing and host damage. Nat Immunol. 2014;15(12):1116-25.

41. Massagué J, Chen YG. Controlling TGF-beta signaling. Genes Dev. 2000;14(6):627-44

42. Shi Y, Massagué J. Mechanisms of TGF-beta signaling from cell membrane to the nucleus. Cell. 2003;113(6):685-700.

43. Massagué J. TGF $\beta$ signalling in context. Nat Rev Mol Cell Biol. 2012;13(10):616-30

44 Lok C Cachexia: The last illness. Nature 2015:528(7581):182-3.

45. Nakajima I, Yamaguchi T, Ozutsumi K, Aso H. Adipose tissue extracellular matrix: newly organized by adipocytes during differentiation. Differentiation. 1998;63(4):193-200.

46. Spencer M, Yao-Borengasser A, Unal R, Rasouli N, Gurley CM, Zhu B, Peterson CA, Kern PA. Adipose tissue macrophages in insulin-resistant subjects are associated with collagen $\mathrm{VI}$ and fibrosis and demonstrate alternative activation. Am J Physiol Endocrinol Metab. 2010;299(6):E1016-1027. 
47. Pasarica M, Gowronska-Kozak B, Burk D, Remedios I, Hymel D, Gimble J, Ravussin E, Bray GA, Smith SR. Adipose tissue collagen VI in obesity. J Clin Endocrinol Metab. 2009;94(12):5155-62.

48. Chu ML, Conway D, Pan TC, Baldwin C, Mann K, Deutzmann R, Timpl R. Amino acid sequence of the triple-helical domain of human collagen type VI. J Biol Chem. 1988;263(35):18601-6.

49. Singh P, Carraher C, Schwarzbauer JE. Assembly of fibronectin extracellular matrix. Annu Rev Cell Dev Biol. 2010;26:397-419.

50. Taleb S, Cancello R, Clément K, Lacasa D. Cathepsin s promotes human preadipocyte differentiation: possible involvement of fibronectin degradation. Endocrinology. 2006;147(10):4950-9.

51. Gioulbasanis I, Patrikidou A, Kitikidou K, Papadimitriou K, Vlachostergios PJ, Tsatsanis C, Margioris AN, Papandreou CN, Mavroudis D, Georgoulias V. Baseline plasma levels of interleukin-8 in stage IV non-small-cell lung cancer patients: relationship with nutritional status and prognosis. Nutr Cancer. 2012;64(1):41-7

52. Ziora D, Jastrzębski D, Adamek M, Czuba Z, Kozielski JJ, Grzanka A, Kasperska-Zajac A. Circulating concentration of markers of angiogenic activity in patients with sarcoidosis and idiopathic pulmonary fibrosis. BMC Pulm Med. 2015;15:113.

53. Borthwick LA, Barron L, Hart KM, Vannella KM, Thompson RW, Oland S, Cheever A, Sciurba J, Ramalingam TR, Fisher AJ, et al. Macrophages are critical to the maintenance of IL-13-dependent lung inflammation and fibrosis. Mucosal Immunol. 2016;9(1):38-55.

54. Wynn TA, Vannella KM. Macrophages in tissue repair, regeneration, and fibrosis. Immunity. 2016;44(3):450-62.

55. van der Velden JL, Guala AS, Leggett SE, Sluimer J, Badura EC, Janssen-Heininger YM. Induction of a mesenchymal expression program in lung epithelial cells by wingless protein (Wnt)/ $\beta$-catenin requires the presence of c-Jun N-terminal kinase-1 (JNK1). Am J Respir Cell Mol Biol. 2012;47(3):306-14.

56. David CJ, Huang YH, Chen M, Su J, Zou Y, Bardeesy N, lacobuzio-Donahue CA, Massagué J. TGF- $\beta$ Tumor Suppression through a Lethal EMT. Cell. 2016:164(5):1015-30.

57. Tsurutani $Y$, Fujimoto $M$, Takemoto $M$, Irisuna $H$, Koshizaka M, Onishi S, Ishikawa T, Mezawa M, He P, Honjo S, et al. The roles of transforming growth factor- $\beta$ and Smad3 signaling in adipocyte differentiation and obesity. Biochem Biophys Res Commun. 2011;407(1):68-73.

58. Samad F, Uysal KT, Wiesbrock SM, Pandey M, Hotamisligil GS, Loskutoff DJ. Tumor necrosis factor alpha is a key component in the obesity-linked elevation of plasminogen activator inhibitor 1. Proc Natl Acad Sci U S A. 1999;96(12):6902-7.

59. Alessi MC, Bastelica D, Morange P, Berthet B, Leduc I, Verdier M, Geel O, Juhan-Vague I. Plasminogen activator inhibitor 1, transforming growth factor-beta1, and BMI are closely associated in human adipose tissue during morbid obesity. Diabetes. 2000;49(8):1374-80.

60. Fain JN, Tichansky DS, Madan AK. Transforming growth factor beta1 release by human adipose tissue is enhanced in obesity. Metabolism. 2005:54(11):1546-51.

61. Dahlman I, Mejhert N, Linder K, Agustsson T, Mutch DM, Kulyte A, Isaksson B, Permert J, Petrovic N, Nedergaard J, et al. Adipose tissue pathways involved in weight loss of cancer cachexia. Br J Cancer. 2010;102(10):1541-8.

62. Zhang YE. Non-smad signaling pathways of the TGF- $\beta$ family. Cold spring harb perspect Biol. 2017;9(2):a022129. doi:10.1101/cshperspect.a022129.

63. Nakayama Y, Komuro R, Yamamoto A, Miyata Y, Tanaka M, Matsuda M Fukuhara A, Shimomura I. RhoA induces expression of inflammatory cytokine in adipocytes. Biochem Biophys Res Commun. 2009;379(2):288-92.

64. Hara Y, Wakino S, Tanabe Y, Saito M, Tokuyama H, Washida N, Tatematsu S, Yoshioka K, Homma K, Hasegawa K, et al. Rho and Rho-kinase activity in adipocytes contributes to a vicious cycle in obesity that may involve mechanical stretch. Sci Signal. 2011;4(157):ra3.

\section{Submit your next manuscript to BioMed Central and we will help you at every step:}

- We accept pre-submission inquiries

- Our selector tool helps you to find the most relevant journal

- We provide round the clock customer support

- Convenient online submission

- Thorough peer review

- Inclusion in PubMed and all major indexing services

- Maximum visibility for your research

Submit your manuscript at www.biomedcentral.com/submit 